\title{
Reuse of waste paper and rice hulls as filler in polymeric matrix composites
}

\author{
Eliana Paula Calegari ${ }^{1}$, Jussara Smidt Porto ${ }^{1}$, \\ Clarissa Coussirat Angrizani ${ }^{2}$, Branca Freitas de Oliveira ${ }^{1}$, \\ Lauren da Cunha Duarte ${ }^{1}$, Sandro Campos Amico ${ }^{2}$
}

\begin{abstract}
${ }^{1}$ PGDesign, Federal University of Rio Grande do Sul, Porto Alegre, RS, Brazil, elianapaulac@gmail.com, jussara.porto@ufrgs.br, branca@ufrgs.br, lauren.duarte@ufrgs.br

${ }^{2}$ PPGEM, Federal University of Rio Grande do Sul, Porto Alegre, RS, Brazil, cangrizani@hotmail.com, amico@ufrgs.br

ABSTRACT

Concerns for the environment are recurrent in our society, and research on low impact materials such as those produced from waste is an alternative. This work is based on the reuse of scrap paper and rice hulls aiming to increase the life cycle of these waste products and to find better destination. Composites with a volumetric filler content (dispersed phase) of $80 \%$ were produced via compression molding using polyurethane (PU) based on castor oil or polyester resin as matrix, in four distinct families: polyester/rice hulls, PU/rice hulls, polyester/paper and PU/paper. The following tests were performed: water sorption, contact angle, hardness, impact and tensile testing. Scanning electron microscopy (SEM) was used for fracture morphology study. Basic visual analysis showed greater void content for the rice hull composites, making them less aesthetically appealing compared to paper. It was observed in the case of PU matrix the filler greatly influenced the rigidity since this pure material was more flexible compared to pure polyester. Filler incorporation decreased tensile strength of the polyester matrix but significantly increased that of the PU matrix.
\end{abstract}

Keywords: Green composites, rice hulls, scrap paper, castor oil based polyurethane, compression molding.

\section{INTRODUCTION}

Sustainable development comprises social, environmental and economic matters, aiming to promote the improvement of life quality and the minimization of environmental impacts. On this context, the design of products has recently focused on the development of less pollutant materials and reduced environmental impact. An option in the development of these materials is related to the production of composites from renewable resources with good physical, mechanical and chemical properties that have the potential to replace non-renewable materials.

The replacement of synthetic fibers for natural ones in composites is mostly based on their low cost and rapid renewability. Brazil can benefit from this scenario considering that it has one of the largest territories in the world for growing crops. According to Rowell et al. [1], vegetable fibers commonly used as reinforcing materials in polymeric composites include sisal, coir, jute and banana, along with wood fibers, sugarcane bagasse and bamboo. As mentioned by Karger-Kocsis et al. [2], many fibers used in composites are regularly cultivated such as cotton, flax and hemp, others are byproducts of plants for food purposes, as cane bagasse, coconut shell, stem of the banana, rice hulls and straw corn. Furthermore, solid waste arising from production processes can have a nobler destination than the disposal in dumps [3] if they are used as filler in non-structural composites, in applications like packaging in agribusiness and in the building sector.

Jearanaisilawong et al. [4] molded rice hulls/polypropylene composites with $5-20 \%$ filler weight fraction. They observed an increase in failure load of the composite at 5\% mass fraction and a decrease for higher weight fractions and the reinforcing effect of rice hull regarding stiffness and elongation at break saturated at around $15 \%$ weight fraction. Miléo et al. [5] obtainment composites of castor oil polyurethane reinforced with cellulose fibers from sugarcane straw $(5,10,15,20 \% \mathrm{wt} / \mathrm{wt})$. The incorporation of cellulose fibers in the matrix showed that the composite stiffness increased when compared to the pure matrix.

Mistri et al. [6] developed castor oil-based composites reinforced with non-woven jute fibers. Composites were tested for their flexural properties, impact strength and dynamic mechanical properties and compared with similar unsaturated polyester resin/jute composites. Compared to polyester/jute composites, flexural modulus of the castor oil/jute composites did not improve, but the impact strength and damping 
properties were much higher. In another study, Boquillon et al. [7] used hemp fibers as natural reinforcement in composites of thermosetting vegetal oil based resin. Boards with fiber content from 0 to $65 \%$ vol were produced by hot pressing. The hemp fiber significantly improved the flexural properties (modulus and strength) of the resulting composites, indicating good fiber-matrix interfacial adhesion, which was confirmed by scanning electron microscopy.

The use of polymers from renewable sources for composites is also advantageous from an environmental point of view. Thus, castor oil based polyurethane (PU) can be an alternative to replace petroleum-based polymers. Castor oil is extracted from the castor bean (Ricinus communis), a plant found in tropical and subtropical regions, abundant in Brazil. From this oil, it is possible to synthesize polyols and prepolymers with different characteristics, that may yield castor oil based PU [8]. With the objective of studying an alternative to the partial recovery of waste generated by the rice and printing industries, this work addressed the use of rice hulls and scrap paper as fillers in polymeric materials (castor oil based PU and polyester resin) in order to generate new materials. The composite materials were molded with a volumetric filler content (dispersed phase) of $80 \%$ for the greatest possible waste utilization.

\section{MATERIALS AND METHODS}

\subsection{Materials}

The rice hulls were obtained from the rice industry located in the state of Rio Grande do Sul, Brazil, and the scrap paper from the printing workshop at UFRGS, Brazil (Figure 1). The castor oil based PU was obtained from Imperveg Company, and the orthophthalic unsaturated polyester resin and benzoyl peroxide initiator were obtained from Elekeiroz (both in Brazil).
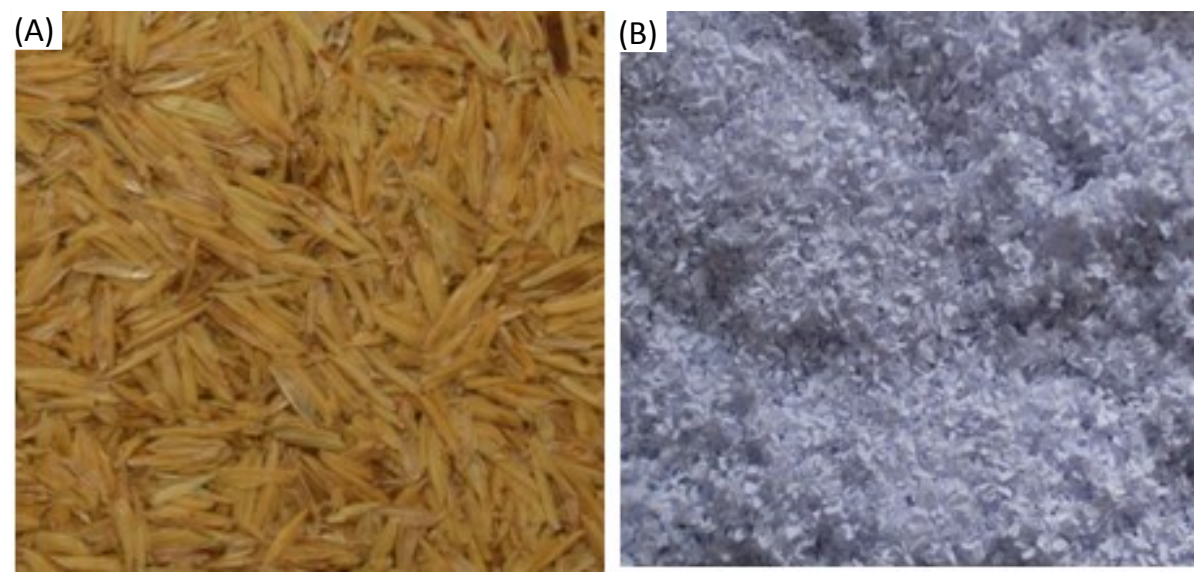

Figure 1: Fillers of composites: A) Rice hulls and B) Scrap paper.

\subsection{Composite preparation}

The rice hulls were oven dried for $24 \mathrm{~h}$ at $60^{\circ} \mathrm{C}$ and the scrap paper for $2 \mathrm{~h}$ at $60{ }^{\circ} \mathrm{C}$. After drying, the matrix (polyester or polyurethane) and fillers were weighed, thoroughly mixed and deposited into a metal mold (inner dimensions: $17 \mathrm{~cm} \times 27 \mathrm{~cm}$ ). The composites were obtained via compression molding, and the compositions are shown in Table 1. The PU composites remained in the hydraulic press (Marconi model MA 098/A) for $24 \mathrm{~h}$ at room temperature and the polyester composites for $75 \mathrm{~min}$ at $80{ }^{\circ} \mathrm{C}$. The samples for the analyses were cut using laser equipment (Automatisa model Mira 3007). Pure polyester and pure polyurethane samples were also obtained for comparison.

Table 1: Composition of the studied composites.

\begin{tabular}{c|c|c|c}
\hline Material & Nomenclature & Matrix Volume Fraction (\%) & Filler Volume Fraction (\%) \\
\hline Polyester/rice hulls & $\mathrm{P} / \mathrm{RH}$ & 20 & 80 \\
\hline Polyurethane/rice hulls & $\mathrm{PU} / \mathrm{RH}$ & 20 & 80 \\
\hline Polyester/scrap paper & $\mathrm{P} / \mathrm{SP}$ & 20 & 80 \\
\hline Polyurethane/scrap paper & $\mathrm{PU} / \mathrm{SP}$ & 20 & 80 \\
\hline
\end{tabular}




\subsection{Characterization}

For water sorption characterization, 5 samples $(5 \mathrm{~cm} \times 5 \mathrm{~cm})$ of each composition were made. Dried samples were weighed on a digital scale (Quimis model Q - 500L210C) and immersed in containers with distilled water at room temperature. After $24 \mathrm{~h}, 48 \mathrm{~h}, 240 \mathrm{~h}$ e $360 \mathrm{~h}$, the samples were removed from the water, the excess water was wiped with a paper towel, and they were weighed. Water sorption (A\%) was calculated according to $A \%=100 \times\left(M_{2}-M_{1}\right) / M_{1}$, where $M_{1}$ is the initial weight of the sample and $M_{2}$ is the final weight.

To determine the contact angle, the water droplet spreading method was used. The procedure consists in depositing a liquid droplet on a flat surface of a horizontally positioned solid. The liquid spreads on the solid surface and achieves an equilibrium contact angle $(\theta \mathrm{e})$ in which the adhesion forces of the solid/liquid are in balance [6]. The liquid used to determine the contact angle was distilled water at room temperature and evaluation was performed in the four composite samples and in the pure polymers. A contact angle meter model LB-DX, coupled with a digital camera, was used for that.

Tensile testing was conducted according to ASTM D3039 in a universal testing machine Instron 3382 (100 $\mathrm{kN}$ load cell with accuracy $0,32 \%$ ) at $2 \mathrm{~mm} / \mathrm{min}$. The elasticity modulus was obtained with an extensometer. Scanning electron microscopy (SEM), on Jeol JSM-6060 equipment operating at $15 \mathrm{keV}$, was used for morphological studies of the tensile-fractured samples.

For shore D hardness measurements, ASTM D2240 was followed and a Model Wultest SD 300 durometer was used to obtain 20 measurements in each sample. The IZOD impact testing was carried out on notched samples according to ASTM D256 using a CEAST Impactor model 2 equipment. Two hammers were used, $0.5 \mathrm{~J}$ and $11 \mathrm{~J}$, for the ductile PU and brittle polyester, respectively. Five samples were used in each test and the results were analyzed with a single-factor ANOVA in commercial software. A confidence level of $95 \%$ was used, and the ANOVA results are presented as lower-case letters in the tables.

\section{RESULTS AND DISCUSSIONS}

The processing of the composites by compression molding resulted in uniform plates. In Figure 2, images of the PU/RH, PU/SP, P/RH and P/SP composites are seen. Regarding the PU/RH and PU/SP samples, the latter had a more uniform visual aspect with less apparent voids on the surface of the composite. An alternative to minimize that would be to crush or grind the rice hulls. The polyester composites (P/RH and P/SP) showed a more satisfactory visual appearance in relation to those with PU, probably because the polyester only hardens after mixing it with the initiator, and PU expands during polymerization producing voids.
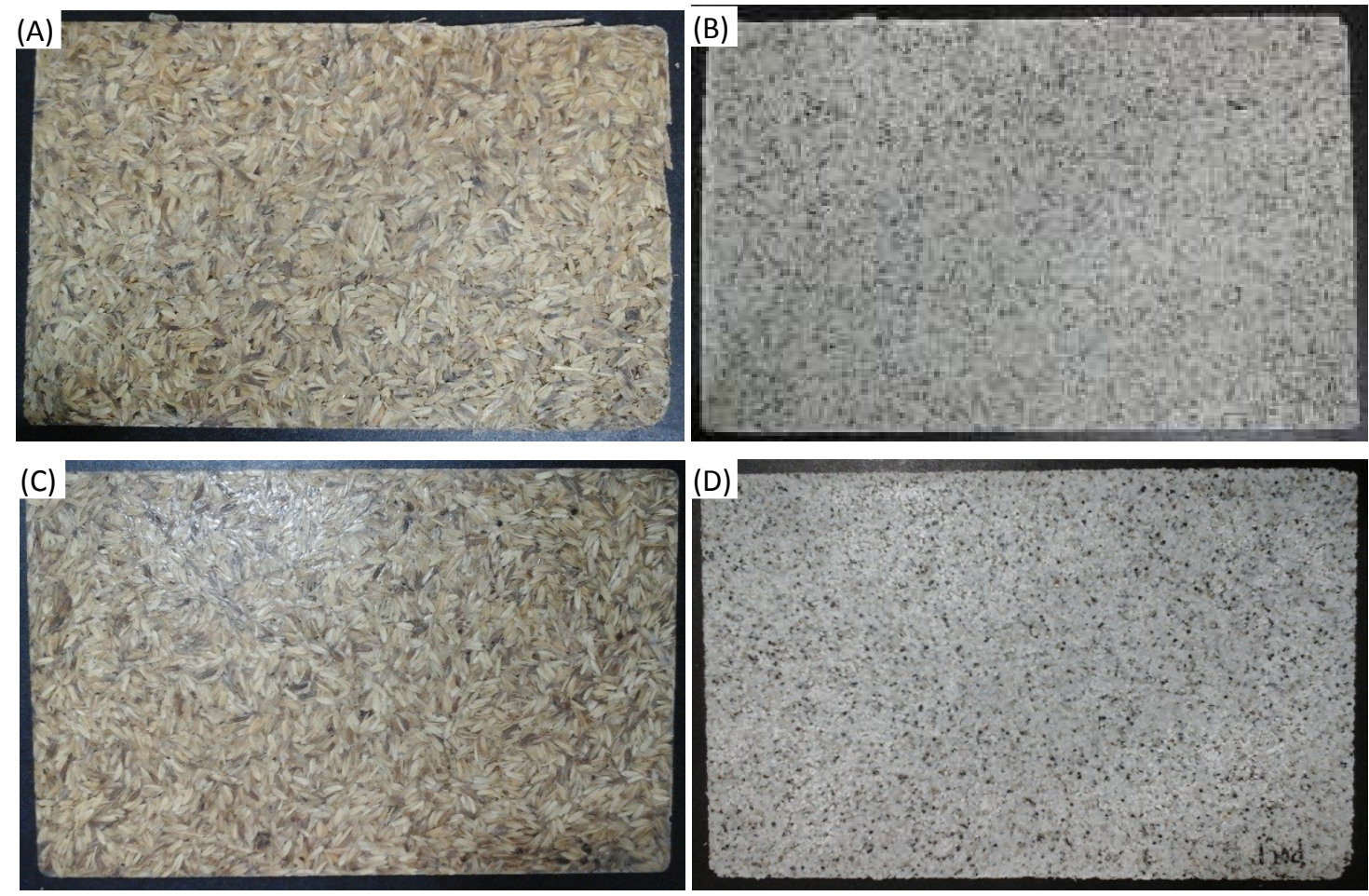

Figure 2: Composites: A) PU/RH, B) PU/SP, C) P/RH and D) P/SP. 


\subsection{Physical characterization}

The measured water sorption of the pure polymers and their composites are shown in Figure 3. Pure polyester and pure PU absorbed less water in all the tested periods. The PU/RH composite displayed 35\% water sorption, whereas the other composites reached $25-30 \%$. Thus, the dispersed phase significantly increased water sorption, which may be associated with the fillers themselves and also with the quality of the final part and the voids present in the composite.

Figure 4 shows images of the equilibrium contact angle obtained in the water droplet spreading test according to [9] where small contact angle indicates that the spread was more pronounced. It can be seen that the contact angle for all samples is less than $90^{\circ}$, consequently the materials can be considered generally hydrophilic. The higher the angle the more hydrophobic is the material. Therefore, the composites are more hydrophilic than the polyester and polyurethane pure. This result confirms the trend observed in the water sorption test.

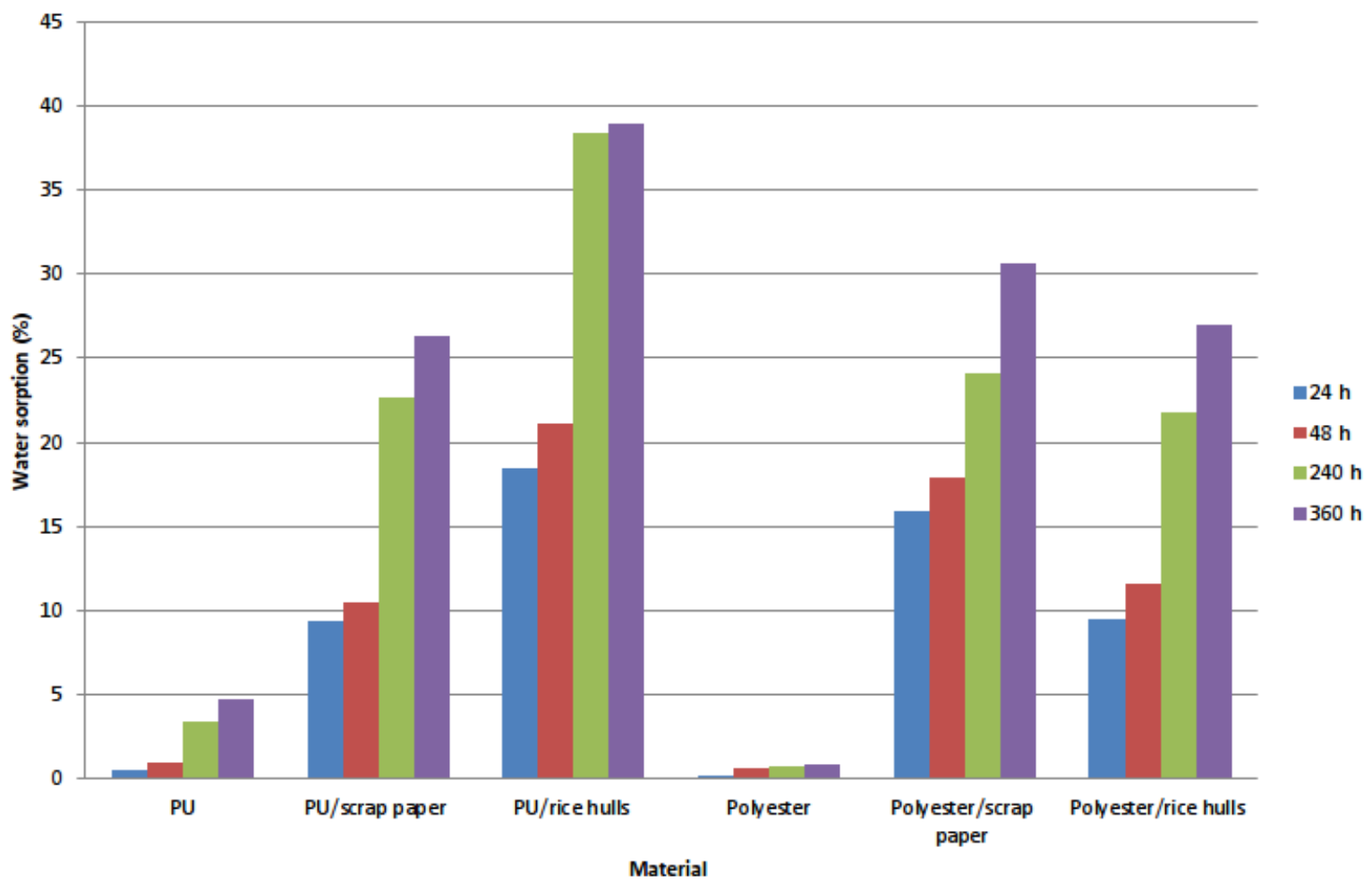

Figure 3: Water sorption of polyester, polyurethane and their composites.

(A)

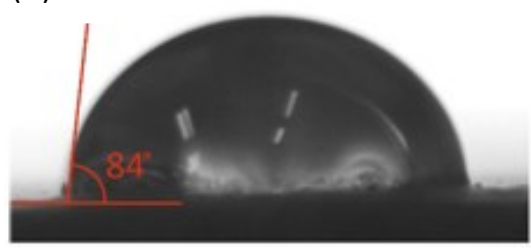

(D)

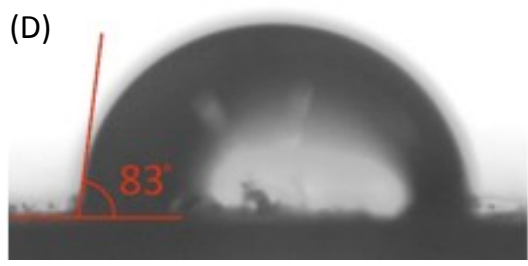

(B)

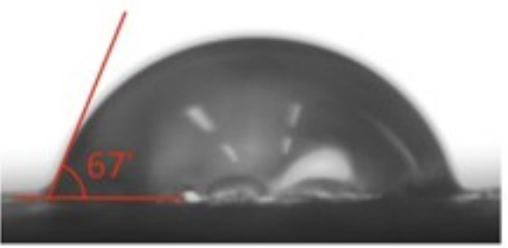

(E)

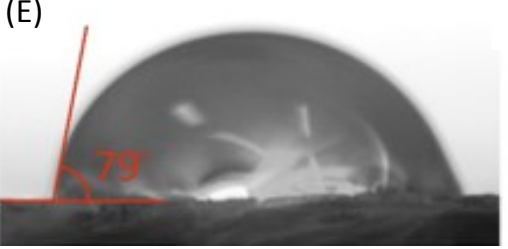

(C)

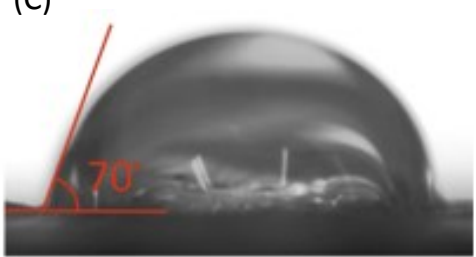

(F)

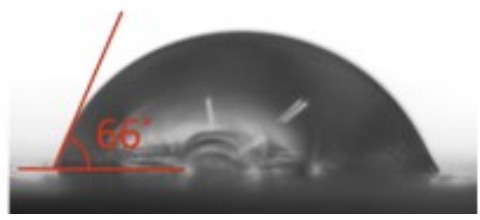

Figure 4: Contact angle measured for: A) PU, B) PU/SP, C) PU/RH, D) P, E) P/SP e F) P/RH. 


\subsection{Mechanical characterization}

Figure 5 shows typical tensile curves for the tested materials. Three profiles were observed, the ductile behavior of PU, the brittle behavior of the polyester, and the intermediate behavior of the composites. It is interesting to notice the significant change in the behavior of the PU curve when the paper filler is added.

Table 2 shows elasticity modulus and tensile strength of the composites. There is an increase in elastic modulus with the insertion of the dispersed phase for both polymeric matrices [2], which was justified by the higher stiffness of the fillers (rice hulls: $2.5 \mathrm{GPa}$ [4] and paper: $>4 \mathrm{GPa}[10]$ ) and the significant amount of filler used ( $80 \%$ in volume). This effect is more pronounced for PU because of its very low original modulus. Based on the ANOVA results, it is possible to verify that, for polyester, the scrap paper was more effective, whereas for PU, both fillers had a similar effect.

In the study of Merlini et al. [11] the tensile strength and Young's modulus increased with increasing banana fiber volume fraction and length for castor oil-based PU composites. For a 15\% vol of untreated banana fiber with lengths of 20 and $30 \mathrm{~mm}$, tensile strength values were 4.33 and $4.80 \mathrm{MPa}$, respectively, which are 120 and $144 \%$ higher than the value for the unreinforced polyurethane.

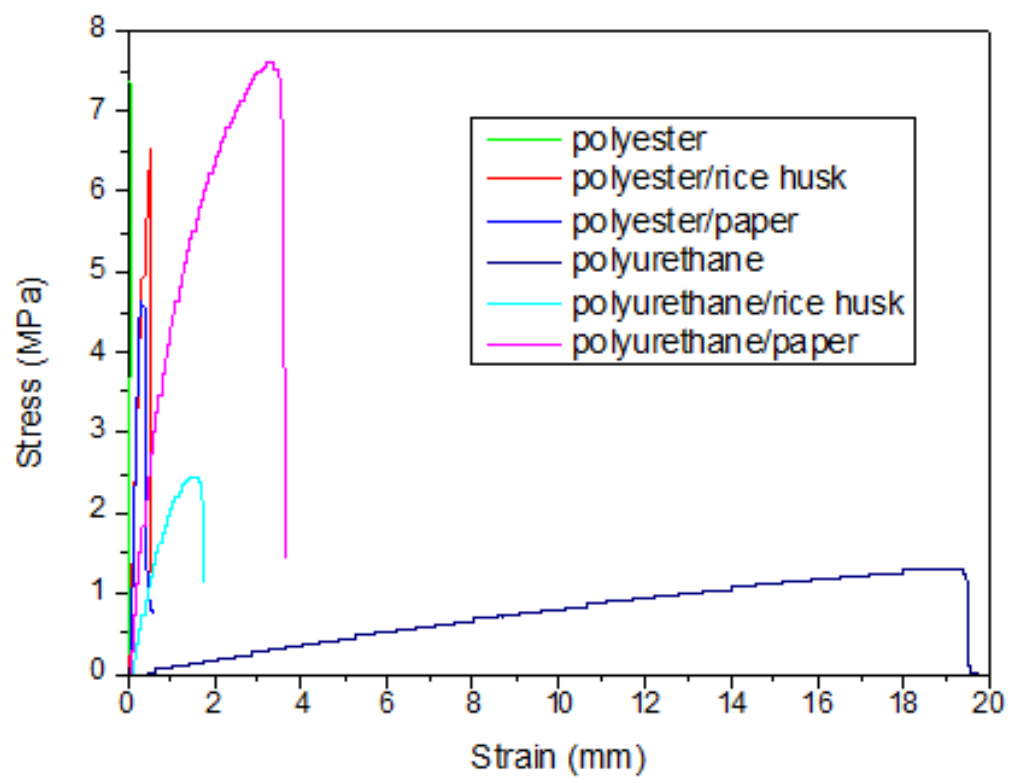

Figure 5: Typical stress vs. strain curves of the studied materials.

Regarding tensile strength (Table 2), PU showed very low strength compared to polyester. The addition of the fillers produced opposite effects on them, i.e. making the polyester weaker and the PU stronger. In this case, ANOVA showed significant differences for all families. Rozman et al. (2003) [12] developed PU/RH composite with different particle sizes and observed higher tensile modulus and strength, for smaller particles. According to the authors, this was expected because smaller size fillers give larger surface area per volume for the interaction between $\mathrm{OH}$ groups from rice hulls with NCO groups from PU.

Table 2: Mechanical properties of composites.

\begin{tabular}{c|c|c}
\hline Samples & Elasticity Modulus (MPa) & Tensile Strength (MPa) \\
\hline Polyester & $2286 \pm 751^{\mathrm{a}}$ & $17.8 \pm 0.5^{\mathrm{e}}$ \\
\hline P/RH & $2490 \pm 436^{\mathrm{a}}$ & $6.3 \pm 0.8^{\mathrm{f}}$ \\
\hline P/SP & $3144 \pm 248^{\mathrm{b}}$ & $4.4 \pm 2.5^{\mathrm{g}}$ \\
\hline Polyurethane & $13 \pm 3^{\mathrm{c}}$ & $1.2 \pm 0.2^{\mathrm{h}}$ \\
\hline PU/RH & $491 \pm 284^{\mathrm{d}}$ & $2.1 \pm 0.4^{\mathrm{i}}$ \\
\hline PU/SP & $741 \pm 113^{\mathrm{d}}$ & $7.8 \pm 0.7^{\mathrm{j}}$ \\
\hline
\end{tabular}


Table 3 shows mean hardness values of the composites. This property was not significantly affected by the insertion of the filler as shown by the ANOVA analysis. Nevertheless, the PU displayed lower hardness because the PU used in this work has elastomeric character. Also related to Table 3, it is clear that

PU has superior impact strength than polyester, absorbing more energy during breaking. Ramis et al. [13] studied polyurethane/polyester blends using dynamic mechanical analysis and verified the presence of two peaks related to relaxation (maximum tan delta) in the PU, unlike polyester (with a single peak), due to the greater mobility and less cross-linked network of the former. This greater mobility helps justifying the higher impact strength of the PU matrix. Regarding the fillers, the composites with paper showed higher impact strength, probably because the paper is non-porous such as rice hulls. Figure 6 shows SEM micrographs of the composites. Samples with rice hulls displayed rougher surface and those with the paper presented more voids between the fibers.

Table 3: Hardness and impact strength of the samples and composites.

\begin{tabular}{c|c|c}
\hline Samples & Hardness (Shore D) & ${\text { Impact Strength } \mathbf{( k J / m} \mathbf{m}^{\mathbf{2}}}$ \\
\hline Polyester & $11 \pm 1^{\mathrm{a}}$ & $1.00 \pm 0.08^{\mathrm{c}}$ \\
\hline P/RH & $11 \pm 1^{\mathrm{a}}$ & $1.26 \pm 0.13^{\mathrm{d}}$ \\
\hline P/SP & $10 \pm 1^{\mathrm{a}}$ & $1.57 \pm 0.22^{\mathrm{d}}$ \\
\hline Polyurethane & $8 \pm 1^{\mathrm{b}}$ & $9.28 \pm 0.96^{\mathrm{e}}$ \\
\hline PU/RH & $9 \pm 1^{\mathrm{b}}$ & $3.4 \pm 0.26^{\mathrm{f}}$ \\
\hline PU/SP & $9 \pm 1^{\mathrm{b}}$ & $9.26 \pm 0.76^{\mathrm{e}}$ \\
\hline
\end{tabular}
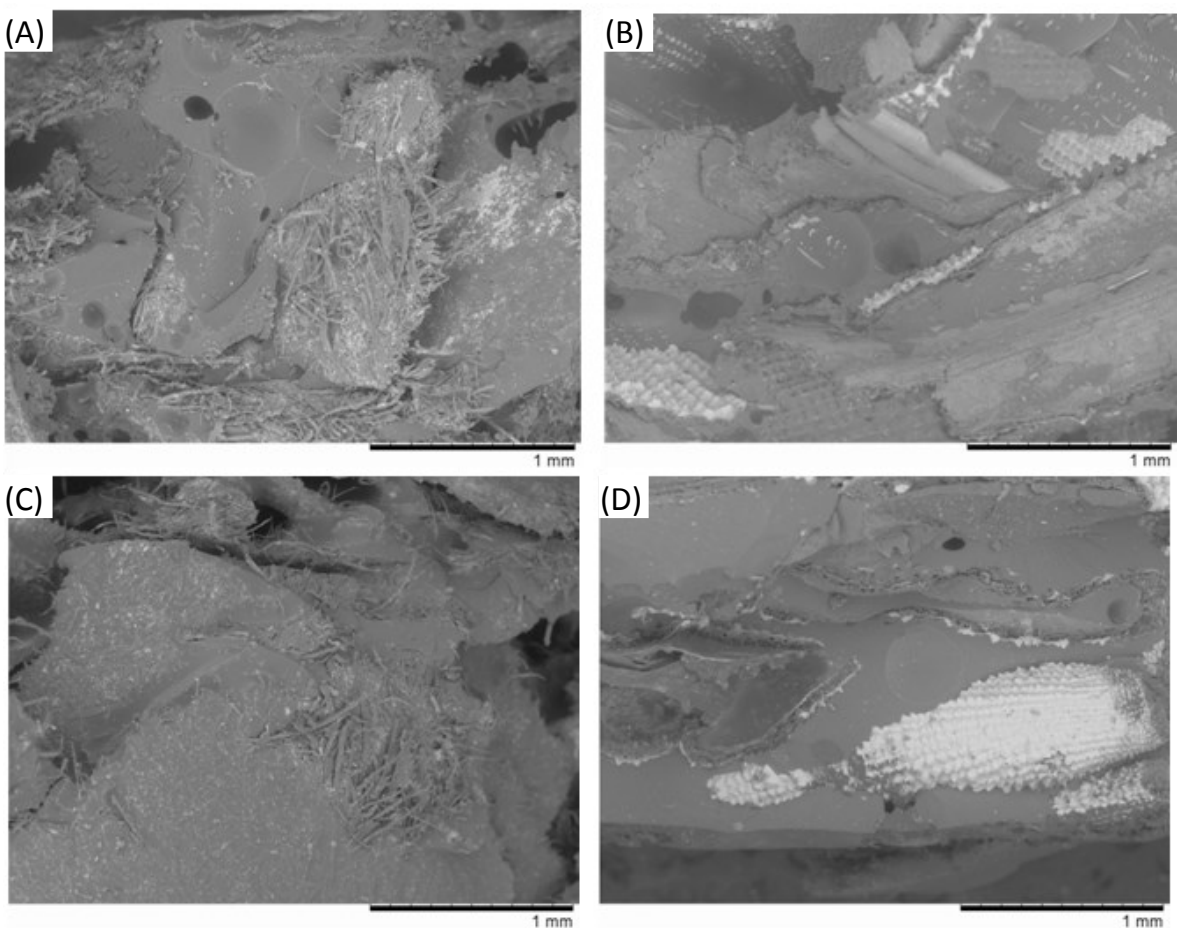

Figure 6: Cross-sectional view of the tensile-fractured surfaces of the samples: A) PU/SP; B) PU/RH; C) P/SP; D) P/RH.

\section{CONCLUSIONS}

The composites produced in this work using polyurethane, polyester, rice hulls and scrap paper were characterized via physical and mechanical tests. Water sorption and contact angle results suggested that the composites are generally hydrophilic materials. In the mechanical tests, the PU/SP composite presented better properties considering the original properties of the pure polymer. The pure PU has flexible, elastomeric character and the insertion of rice hulls and paper increased its stiffness.

Taking into account the feedstock source of the composites developed in this work and the results obtained with the incorporation of the filler, it is possible to point out that the PU provided a material with several potential applications and also more positive environmental aspects since it is derived from renewable 
source. Nevertheless, the polyester composites are also interesting because the volumetric fraction of the fillers reached $80 \%$, that is, the waste (rice hulls and scrap paper) corresponded to most of the material. Thus, the composites developed in this research can be used for product design applications driven by sustainability.

\section{ACKNOWLEDGEMENTS}

The authors thank CAPES for their financial support, Imperveg S.A. for providing the castor oil based polyurethane and Elekeiroz S.A. for providing the polyester resin.

\section{BIBLIOGRAPHY}

[1] ROWELL, R.M., SANDI, A.R., CAULFIED, D.F., et al., "Utilization of natural fibers in plastic composites: Problems and opportunities", In: lignocellulosic: plastics composites, São Paulo, Universidade de São Paulo, pp. 23 - 52, 1997.

[2] KARGER-KOCSIS, J., MAHMOOD, H., PEGORETTI, A., "Recent advances in fiber/matrix interphase engineering for polymer composites", Progress in Materials Science, v. 73, pp. 1 - 43, 2015.

[3] MACHADO, A.R.T., MARTINS, P.F.Q., FONSECA, E.M.B., et al., "Compósitos biodegradáveis a base de polihidroxibutirato-hidroxivalerato (PHB-HV) reforçados com resíduos do beneficiamento do café", Revista Matéria, v. 15, n. 3, pp. 400 - 404, 2010.

[4] JEARANAISILAWONG, P., EAHKANONG, S., PHUNGSARA, B., et al., "Determination of in-plane elastic properties of rice husk composite", Materials and Design, v. 76, pp. 55 - 63, 2015.

[5] MILÉO, P.C., MULINARI, D.R., BAPTISTA, C.A.R.P., et al., "Mechanical Behaviour of Polyurethane from Castor oil Reinforced Sugarcane Straw Cellulose Composites”, Procedia Engineering, v. 10, pp. 20682073, 2011.

[6] MISTRIA, E., ROUTHB, S., RAYB, D., et al. "Green composites from maleated castor oil and jute fibres”, Industrial Crops and Products, v. 34, pp. 900 - 906, 2011.

[7] BOQUILLON, N. "Use of an epoxidized oil-based resin as matrix in vegetable fibers-reinforced composites", Journal of Applied Polymer Science, v. 101, pp. 4037 - 4043, 2006.

[8] DIAS, F.M., LAHR, F.A.R., “Alternative castor oil-based polyurethane adhesive used in the production of plywood", Materials Research, v. 7, n. 3, pp.413 - 420, 2004.

[9] LAZGHAB, M., SALEH, K., PEZRONI, I., et al., "Wettability assessment of finely divided solids", Powder Technology, v. 157, pp. 79 - 91, 2005.

[10] PRAMBAUERA, M., PAUliK, C., BURGSTAller, C., "The influence of paper type on the properties of structural paper - polypropylene composites", Composites: Part A, v. 74, pp. 107 - 113, 2015.

[11] MERLINI, C., SOLDI, V., BARRA, G.M.O. "Influence of fiber surface treatment and length on physicochemical properties of short random banana fiber-reinforced castor oil polyurethane composites", Polymer Testing, v. 30, pp. $833-840,2011$.

[12] ROZMAN, H.D., YEO, Y.S., TAY, G.S., et al., "The mechanical and physical properties of polyurethane composites based on rice husk and polyethylene glycol”, Polymer Testing, v. 22, pp. 617 - 623, 2003.

[13] RAMIS, X., CADENATO, A., MORANCHO, J.M., et al., "Polyurethane - unsaturated polyester interpenetrating polymer networks: thermal and dynamic mechanical thermal behavior", Polymer, v. 42, n. 23, pp. $9469-9479,2001$ 